\title{
Mapping Stakeholder Perspectives on Engagement in Concussion Research to Theory
}

\author{
Cindy Hunt, Miranda de Saint-Rome, Carol Di Salle, Alicja Michalak, \\ Ruth Wilcock, Andrew Baker
}

\begin{abstract}
Background: Involving stakeholders has been acknowledged as a way to improve quality and relevance in health research. The mechanisms that support effective research engagement with stakeholders have not been studied in the area of concussion. Concussion is a large public health concern worldwide with billions of dollars spent on health care services and research with improvements in care and service delivery not moving forward as quickly as desired. Enabling effective stakeholder engagement could improve concussion research and care. Objective: The aim of the study was to identify potential benefits, challenges, and motivators to engaging in research by gathering the perspectives of adults with lived experience of concussion. Methods: A thematic analysis of qualitative responses collected from a convenience sample attending a provincial brain injury conference $(n=60)$ was undertaken using open coding followed by axial coding. Results: Four themes regarding benefits to engagement emerged: first-hand account, meaningful recovery, research relevance, and better understanding of gaps. Three forces inhibited engagement: environmental barriers, injury-related constraints, and personal deterrents. Four enablers supported engagement: focus on positive impact, build connections, create a supportive environment, and provide financial assistance. Conclusions: Understanding stakeholder's perspectives on research engagement is an important issue that may serve to improve research quality. There may be unique nuances at play with injury-specific stakeholders that require researchers to consider a balance between reducing inhibitors while supporting enablers. These findings are preliminary and limited. Nevertheless, they provide needed insight and guidance for ongoing investigation regarding improvement of stakeholder engagement in concussion research.
\end{abstract}

RÉSUMÉ: Répertorier les perspectives des parties prenantes quant à leur implication dans les recherches portant sur les commotions cérébrales. Contexte: Il est admis que l'implication des parties prenantes de la recherche en santé permet d'améliorer la qualité et la pertinence des travaux menés. Cela dit, les mécanismes qui appuient de façon efficace cette implication n'ont pas encore été étudiés en ce qui concerne le domaine d'expertise qui concerne les commotions cérébrales. On le sait, les commotions cérébrales demeurent un important enjeu de santé publique à l'échelle mondiale. Bien que des milliards de dollars soient dépensés chaque année en recherche et en soins de santé, il n'empêche que les avancées en matière de prestation de services ne se concrétisent pas aussi rapidement que l'on souhaiterait. Bref, le fait de favoriser une implication efficace de ces parties prenantes pourrait avoir pour effet d'améliorer la recherche et les soins destinés aux victimes de commotions cérébrales. Objectif: Le but de cette étude est donc d'identifier les bénéfices potentiels et les défis liés à cette implication de même que les éléments motivateurs d'une implication dans la recherche en recueillant les points de vue d'adultes qui ont vécu une commotion cérébrale. Méthodes: Nous avons effectué une analyse thématique des réponses collectées auprès d'un échantillon de commodité $(\mathrm{n}=60)$ ayant assisté à une conférence provinciale portant sur les traumatismes crânio-cérébraux (TCC). Pour ce faire, nous avons utilisé des techniques de codification ouverte et axiale. Résultats: Dans l'ensemble, quatre thèmes au sujet des bénéfices de l'implication ont émergé : les témoignages personnels, le fait de récupérer réellement, la pertinence de la recherche et une meilleure compréhension des carences en matière de soins. Parmi les facteurs qui nuisent à l'implication des parties prenantes, trois sont ressortis: des obstacles liés au milieu, des contraintes liées à la commotion elle-même et des éléments dissuasifs de nature personnelle. Cela dit, quatre facteurs de nature à favoriser l'implication peuvent être signalés : mettre l'accent sur l'impact positif de l'implication, établir des liens, créer des milieux propices au soutien et fournir de l'aide financière. Conclusions: Comprendre les points de vue des parties prenantes quant à leur implication dans le domaine de la recherche demeure un enjeu de premier plan qui pourrait contribuer à améliorer la qualité des travaux de recherche. Il se peut que les chercheurs aient à tenir compte de nuances et à envisager un équilibre entre le fait de réduire le poids des facteurs dissuasifs et de favoriser les éléments qui favorisent l'implication. Chose certaine, ces résultats, même s'ils demeurent

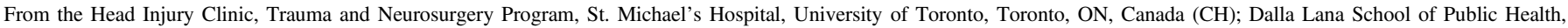

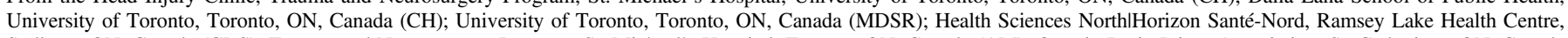

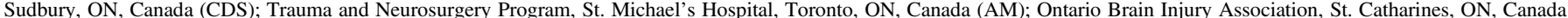

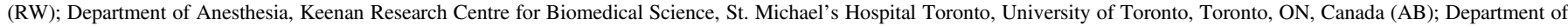
Critical Care, Keenan Research Centre for Biomedical Science, St. Michael's Hospital Toronto, University of Toronto, Toronto, ON, Canada (AB)

Received May 28, 2019. Final Revisions Submitted October 25, 2019. Date of Acceptance November 4, 2019.

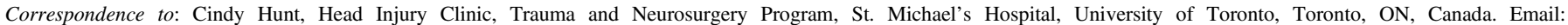
Cindy.Hunt@unityhealth.to 
préliminaires et limités, nous offrent un aperçu et des indications nécessaires en vue de recherches en cours portant sur l'amélioration de la participation des parties prenantes dans les recherches qui portent sur les commotions cérébrales.

Keywords: Concussion, Mild traumatic brain injury, Stakeholder engagement, Research doi:10.1017/cjn.2019.324

\section{BACKGROUND}

The desire to enhance the quality of research studies is a driving force behind stakeholder engagement research (SER). SER is increasingly being recognized as promoting relevance of research aims to real world issues, improving participant recruitment and retention, and enhancing knowledge dissemination. ${ }^{1-4}$ The shift toward stakeholder involvement in health research was first reported in 1996 by the National Institute for Health Research, INVOLVE project in the UK. ${ }^{5}$ In 2010, the US funded studies engaging stakeholders in research in the program called Patient-Centered Outcomes Research (PCORI). ${ }^{6}$ Shortly thereafter in 2011, the Canadian Strategy for Patient Oriented Research ${ }^{7}$ emerged with principles similar to the UK and US programs aiming to support, promote, and co-build research with stakeholders. Despite more than two decades of defining statements and funding SER, there is limited evidence to inform efforts to produce practical and meaningful strategies on the mechanisms, processes, and supports for successful implementation. ${ }^{8-11}$ In addition, research is needed to truly understand how to persuade and support engagement under special health conditions. ${ }^{12}$ More recently, reports of SER have been tailored to distinct health populations. ${ }^{13}$ such as adults with cardiovascular disease, ${ }^{14}$ cancer, ${ }^{15}$ and kidney disease, ${ }^{16}$ resulting in potential knowledge on stakeholder engagement strategies targeted to specific illness or injured populations.

Concussion is a global public health concern accounting for $80 \%$ of the $64-74$ million traumatic brain injuries worldwide annually. ${ }^{17}$ Concussions are responsible for $\$ 1.5$ billion per year in acute hospital costs in Canada and far more in indirect costs, primarily from community-based health care use and productivity loss in patients with prolonged symptoms. ${ }^{18}$ While most adult patients recover within 7-10 days, an estimated 15-40\% of cases experience prolonged symptoms, lasting 3 months or longer which cause stress and disability. ${ }^{19-22}$ Symptoms can include cognitive, physical, sleep, and emotional disturbances. ${ }^{20-22}$ In spite of millions more health dollars spent on research, clear reasons for these differences in recovery post-concussion are not well understood. ${ }^{19}$

Qualitative interviews with families of concussed children involved in one research study resulted in improvements to clinical protocols, reduced questionnaire length, adjustments to knowledge translation activities, and the addition of stakeholders to the advisory committee. ${ }^{23}$ There are many adult concussion studies that engage stakeholders as part of formative research, ${ }^{19,22,24}$ although to date researchers have not done an optimal job in explaining how or what strategies have been used for engaging stakeholders. Our study aims to take steps toward addressing this knowledge gap. The primary objective was to identify potential benefits, challenges, and motivators to engaging in research by gathering the perspectives of adults with lived experience of concussion. The secondary objective was to begin to fit themes identified from participant responses into theory and modify an existing conceptual framework in order to inform, support, and evaluate SER in future studies of concussion.

\section{Methods \\ Study Design, Setting, and Participants}

A convenience sample of adults attending a two-day provincial acquired brain injury (ABI) conference held in southeastern Ontario participated in the study. The mission of the organization hosting the conference was to enhance the lives of those living with ABI through education, awareness, and support. ${ }^{25}$ The theme of the conference was "Making a Difference". The ABI conference attracted front-line rehabilitation professionals such as Case Managers, Occupational Therapists, Physiotherapists, Psychologists, Speech and Language Pathologists, Researchers as well as persons living with the effects of an ABI (including family members and caregivers with the experience of concussion). We defined stakeholders as persons living with the experience of concussion, which included a personal injury or a relationship with someone who experienced concussion (family member or a client). Participants could select more than one category to describe their stakeholder status. Close to one third of the stakeholders had experienced their own concussion, while one-half worked as healthcare providers and/or worked in a community-based organization that supported people with a brain injury. The study received ethical approval from both St. Michael's Hospital Review Ethics Board and the executive team hosting the conference.

\section{Study Measures}

Study participants had the option to complete the questionnaires online or on paper. Information gathered included demographics, birth sex and the first three digits of the postal code, and a multiple choice question to identify their preferred level of research engagement. Options spanned the engagement continuum: inform: low level of input and influence such as reading communications and fact sheets that educate, consult: being part of the information gathering such as focus group or by survey participation, involve: mid-level of input and influence such as providing dialog and feedback on a project/study, collaborate: experience based partnership, or empower: high level of input and influence such as being a partner decision maker in a study. ${ }^{26}$ Three separate open-ended questions invited participants to describe their views regarding the benefits, challenges, and motivators to engaging in concussion research activities.

\section{Data Analysis and Trustworthiness}

Demographic data, stakeholder type, and preferred engagement were summarized using descriptive statistics (see Table 1). 
The qualitative data from the open-ended questions were analyzed using a thematic analysis including open and axial coding. ${ }^{27}$ Open coding involved breaking down information into common groupings based on shared ideas, while axial coding involved organizing information according to overarching themes. ${ }^{27}$ Our research team included health professionals with diverse practice backgrounds and many years of experience in concussion care and research (nursing, speech and language pathology, social work, critical care physician, public health science, and psychology). Two investigators ( $\mathrm{CH}$ and $\mathrm{MD}$ ) systematically and inductively coded all responses. The coding scheme was shared with all investigators after the first 10 responses to discuss the evolving coding scheme. Codes were sorted into preliminary themes to identify inhibitors and enablers, which emerged from the interpretative lens of team members. Findings were discussed among the larger research team with highlighting supporting quotes. Priority was given to themes that were more common and to themes the team felt essential to the perspective of factors affecting research engagement. The codes discussed aligned with perceptions of forces that inhibit engagement and strategies that enable engagement. Key codes were selected and themes abstracted with corresponding quotes. Discrepancies were reconciled through discussion between three team members $(\mathrm{CH}, \mathrm{MD}$, and $\mathrm{CD})$. Strategies to ensure trustworthiness and credibility of the data included having different coders to establish inter-coder reliability and employing an iterative approach to analysis.

\section{Results}

As outlined in Table 1, 11 males and 49 females consented to participate in the study how they would like to be involved in health research. Almost half of the respondents selected passive engagement: informing and/or consulting (24/60 and 25/60, respectively), while one in five participants chose more active engagement, empower (11/60) (see Figure 1). The frequency and percentage of responses to benefits, inhibitors, and enablers to stakeholder engagement in concussion are presented in Table 2. Response themes are presented below.

\section{Benefits of Engagement}

First-hand account, meaningful recovery, research relevance, and better understanding of the service gaps.

Analysis of the participant responses to perceived benefits of stakeholder engagement in research yielded four themes. Firsthand account was commonly expressed among one-third of respondents. The importance of practical, real-world day-to-day life experience from concussion and the recognition that individuals with lived experience have a deep understanding of concussion was expressed. Stakeholders felt they offered real stories and more accurate views of daily life of a person with a concussion and their family.

Better understanding of what life is really like, not best guess and improved understanding of different struggles based on where we live and who we are. (P22)

Obtaining actual verbal feedback and not just learning from academic printed material. Some things you need to hear from those who have been there. (P48)

They have the most information. (P3)
Table 1: Demographic characteristics of study participants

\begin{tabular}{l|c}
\hline Demographics & Frequency, $\boldsymbol{n}=\mathbf{6 0}(\boldsymbol{\%})$ \\
\hline Sex & $11(18.3)$ \\
\hline Male & $49(81.7)$ \\
\hline Female & $21(35)$ \\
\hline Lived experience of concussion* & $15(25)$ \\
\hline Personal & $28(47)$ \\
\hline Family member & $27(45)$ \\
\hline Health care work & $19(32)$ \\
\hline Community work & $22(37)$ \\
\hline Place of residence (ON) & $6(10)$ \\
\hline Central & $8(13)$ \\
\hline Western & $5(8)$ \\
\hline Eastern & \\
\hline Northern & \\
\hline Outside & \\
\hline
\end{tabular}

*Multiple responses possible.

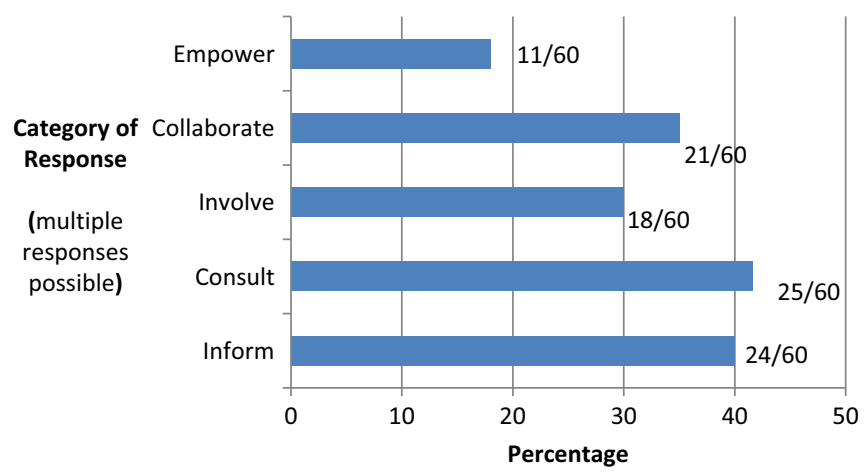

Figure 1: How would you like to be more involved in research?

Meaningful recovery was the second most common benefit stakeholders voiced. Views expressed engagement could be meaningful in the recovery phase of concussion by empowering individuals, providing opportunities to share experience, and supporting others, potentially improving the lives of others.

Such a wide variety of symptoms and issues with concussion, need to brainstorm ideas with people who have been there. Make us feel better and help others. (P24)

To inspire others going through challenging times and to inspire professionals, that they do make a difference. (P51)

By sharing stories-learn from other. Everyone's experiences are different. Find out what works and what does not. (P44)

One-quarter of participants felt the greatest benefit to engagement was that research will be relevant. The 'experience-based knowledge' (as stated by stakeholders) can be key to research with impact.

The people who have been through a concussion truly know the biggest issues. (P60) 
Table 2: Frequency and percentage of responses to benefits, inhibitors, and enablers to stakeholder engagement in concussion

\begin{tabular}{l|c}
\hline Themes & Frequency (\%) \\
\hline Benefits & $n=57$ \\
\hline First-hand account & $17(29.8)$ \\
\hline Meaningful recovery & $17(29.8)$ \\
\hline Research relevance & $15(26.3)$ \\
\hline Better understand gaps & $8(14.0)$ \\
\hline Inhibitors* & $n=56$ \\
\hline Environmental barriers & $29(51.8)$ \\
\hline Injury-related constraints & $23(41.0)$ \\
\hline Personal Deterrents & $11(19.6)$ \\
\hline Enablers* & $n=55$ \\
\hline Focus on the positive & $24(43.6)$ \\
\hline Build connections & $14(25.5)$ \\
\hline Supportive environments & $14(25.5)$ \\
\hline Financial assistance & $6(10.9)$ \\
\hline
\end{tabular}

*Multiple responses possible.

Those we are treating should tell what they need, not top down but bottom up. (P23)

You can gain a clear perspective and discover new ways to smooth the journey. (P27)

Fewer responses acknowledged that SER could provide better understanding of the gaps in service. Participants expressed that engagement could improve systems of care, by sharing stories of what is working and not working. Others suggested that sharing challenges can help to educate the system on needed services and programs.

Engagement could provide opportunities to help mold individual treatment plans and share strategies to improve care. (P12)

Increased understanding of the effects of concussion can help improve so as to improve treatment of the challenges they face. (P6)

They are the experts and we need to know their needs and provide specific supports to improve quality of life. (P49)

\section{INHIBITORS AND ENABLERS}

In analyzing participant responses to the open-ended questions on challenges and motivators, and based on the responses that emerged, we termed the opposing themes inhibitors and enablers. These forces exhibited a "push or pull" toward SER. We defined inhibitors as elements that might impede or hinder RE and enablers as elements to promote successful engagement.

\section{Inhibitors}

\section{Injury-Related Constraints}

Themes emerged around three forces that stakeholders perceived could inhibit involvement in research activities: injury-related constraints, environmental barriers, and personal deterrents. Two categories emerged under injury-related constraints that stakeholders perceived could restrict engagement in research; social and symptom. Social-"having bad days" $(13 / 56=23.2 \%)$ were constraints that encompassed feeling alone, isolated, overwhelmed, and shyness. Others suggested the reluctance to engage in research may be due to a social bias which meant holding the perspective that one person's experience with concussion may not be reflective of the common concussion injury experience.

One person's point of view may be a misplaced perspective and may be an inaccurate view and can bias the research findings. (P29)

The second category within injury-related constraints was symptoms: physical, cognitive, and emotional $(12 / 56=21.4 \%)$. Many participants expressed the burden of ongoing post-concussion symptoms could be a constraint to involvement in research. Different types of symptoms were acknowledged. Over half of the participants suggested patients suffer cognitive symptoms, such as difficulty reading, trouble looking at a computer, and cognitive fatigue. Memory problems, forgetfulness, and memory loss were also considered to be troublesome for some patients. Others may generally feel unwell, have ongoing fatigue and difficulty managing symptoms.

People are often overwhelmed with symptoms sometimes just getting by day-to-day. (P14)

Becoming symptomatic during the research meetings could be a setback for the patient. (P23)

\section{Environmental Barriers}

Culturo-linguistic tensions, time-related factors, financial concerns, and silos and obstacles within the health care system were the categories that emerged under the theme of environmental barriers that made it difficult for SER.

Culturo-Linguistic Tensions $(7 / 56=12.5 \%)$. Several responses commented that when English is not the first language, people are often not eligible or considered for study participation or as a stakeholder. Another participant expressed concern that Indigenous alternative ways of knowing is not supported in many research studies. Others expressed concerns that most stakeholders usually lack the knowledge and skills for research. They felt they may stand in the way of research.

First Nations 'ways of knowing' as a research strategy is often not acknowledged as important. (P52)

I do not have the jargon and do not want to cause the researcher any delays. (P23)

Time-Related Factors $(7 / 56=12.5 \%)$. Many participants reported time as a major barrier to engagement. Time spent searching for the physical location of the research, travel time, and expectations of more time to commit to future meetings would involve too much time. Several commented that many are not prepared to make a lengthy time commitment. Others suggested the patient needed their time open and available to 
attend pending specialty concussion care appointments and as such could not promise to participant in any research engagement activities.

Often participants are expected to come back more than once to the location of the research. It can be very time consuming and overwhelming. (P34)

Keeping them involved in the process and the amount of time that is required to do this. (P54)

Financial Concerns $(10 / 56=17.9 \%)$. Most study participants identified transportation costs to and from the research location and the costs of missed work as major constraints. Stakeholders identified that people with concussion can experience financial struggles for a variety of reasons including being off work, paying out of pocket for assessment, and/or treatment, and as such, participating in research activities may add to their financial burden.

I do not have the time I need the income and need to get back to work. (P48)

Lack of funds, transportation costs, unable to take time away from work. (P29)

Silos and Obstacles $(5 / 56=8.9 \%)$. Several study subjects identified silos and obstacles to research involvement at two levels: health care service and the workplace. Participants expressed that any delays in delivery of required health services interfere with the ability to be involved in research. They explained that waiting for approval to receive funds for transportation to health care services and/or lengthy wait times for specialty care post-concussion services meant they cannot plan for being involved in any type of research activities. Negative experiences in the health care system can dissuade people with lived experience of concussion to engage in research. Those in rural areas experienced more challenges if required to travel to urban locations. Many participants commented that silos contribute to missed diagnosis of concussion resulting in people "falling through the cracks" and missing out on necessary services for care and learning about research opportunities. Research participants are often recruited via specialized concussion clinics. If health service providers or community support associations are not connected to the research, it limits both the research and stakeholders ability to engage.

Poor or very limited access to publicly funded rehabilitation service, with lack of funds and delays in services needed is troublesome and can be a large barrier to having an interest in research. (P23)

Dealing with silos in health care system and with reluctant insurers in the workplace puts many obstacles in the way of getting support for health care that the injured person is entitled. (P10)

I wish it was not so silo-ed which wastes time coordinating between care providers. (P49)

\section{Personal Deterrents}

Two categories of personal deterrents emerged, not seeing the big picture and vulnerability and fear.
Lack of Obvious Benefit for Self or Others (7/56 = 12.5). Several respondents commented that often the inability to see any direct personal benefit to research engagement is a deterrent. Others suggested the level of acceptance with their injury may also impact engagement.

Engaging in research might require a large effort to the participant who may or may not experience a direct benefit. (P22)

Will I actually have an impact by participating? (P15)

Vulnerability and Fear $(4 / 56=7.1 \%)$. Several participants suggested engagement in research could be perceived as harmful to recovery and at times may aggravate post-concussion symptoms. Others suggested patients may feel vulnerable about engagement in research if they are involved in litigation. One respondent speculated that if a patient is involved in a motor vehicle collision, the details may be shared in a research activity that may lead to privacy concerns and fear that it may impact their future compensation.

I am also concerned at times about limited support to patients after engaging in research studies. They may feel overwhelmed with more they have to do, and have increased anxiety and stress which can cause more symptoms. (P11)

I do not want to increase my anxiety; I fear setbacks and privacy concerns. (P18)

Sometimes their legal position may be at risk and privacy concerns related to the injury. (P25)

\section{Enablers}

Four key enabler themes for research engagement arose, providing insights to begin to overcome the forces that restrict engagement.

\section{Positive Motivators}

Almost all subjects stated that research teams need to stress to potential participants that their engagement can make a positive difference to others. A primary motivator identified was communication about the importance of research, so participants know their experiences could help improve the recovery and the lives of others. In addition, communicating that SER will contribute to improving programs and services was also described. Others stated the research team need to recognize there may be different motivators for different stakeholders.

Just ask me. (P45)

Just to know that what I am sharing is further educating people in my community. (P53)

First and foremost, understanding how I might make a difference in the lives of others who also have this injury, so they have a better experience. (P15)

\section{Building Connections}

One third of respondents stressed engagement could also be strengthened by providing opportunities to build connections. 
The connections could occur with a variety of stakeholders, with peers, with health care providers, with institutions and/or with research teams.

Meeting other peers who are having similar life experiences is helpful to normalize and form a sense of community it helps to know that they are not alone. (P22)

Participating can make a difference for our communities and helping with the latest research to improve lives. (P13)

\section{Financial Incentives}

Many acknowledge that families with an injured adult have financial challenges. Funding could be used help to cover transportation costs to the research location, while another suggested costs for accommodation could support participants who want to engage but do not live in major centers, where much of the research tends to occur.

We live in a smaller community so when we travel to major center ..., we travel off-peak hours to avoid traffic, MVCs $\&$ take toll routes like 407 to reduce travel time/stress/ fatigue to injured person \& stay overnight so injured person is less fatigued for meetings. (P18)

I think monetary incentives are helpful as many individuals financially compromised. (P29)

\section{Supportive Environments}

Cultivating a comfortable physical space to share research activities was identified. Setting a different pace for research that is calm and short and non-judgmental was described.

Calm setting, easy access, short meetings, things that can be done at home. (P26)

A different pace of research delivery is needed, short sessions, no jargon, and perhaps small focus groups. (P40)

Finding groups or spaces in which they feel comfortable sharing their story without judgment. (P43)

\section{Discussion}

Despite the growing interest in demand for research that engages stakeholders, few studies on post-concussion explicitly report the details on the mechanisms employed to recruit and sustain or evaluate SER. We explored perspectives on research engagement from adults with experience of concussion attending a provincial brain injury conference. Our efforts likely favored a more research-engaged study sample as compared to the general population by virtue of their attendance at a brain injury conference. Some study participants reported a desire to be more involved in research, beyond the basic level of research subject, again perhaps not that surprising due to their conference attendance. Nevertheless, some of our study findings do line up with other authors' observations on engagement. For example, lack of time for engaging in research was described by many respondents as the greatest barriers to SER, a finding reported in other studies no doubt due to the universal application. ${ }^{28-32}$ Culturo-linguistic tensions we defined as the lack of recognition of Indigenous "ways of knowing". In contrast, other authors referred to cultural barriers as a "power imbalance" between researchers and participants with SER sometimes viewed as acts of tokenism. ${ }^{2,9,15,31}$ Similar to other reports, respondents claimed constraints from patient symptoms of fatigue and anxiety could deter SER. ${ }^{29,30}$ Based on our findings related to the severity of symptoms that impede engagement, it may be beneficial to prioritize stakeholder inclusion in research to patients who have gotten through the acute stages of injury recovery to minimize exacerbation of acute symptoms and avoid contributing to the development of prolonged symptoms.

Using a concussion-specific approach to describe barriers to SER yielded terms of "underservice" and "symptom invisibility". These barriers were not reported in the general engagement literature we reviewed. We speculate there is a need for future studies to explore SER with an injury-specific "lens" since unique mechanisms and barriers to engagement may be overlooked in studies using generic or mixed (disease and injury) study populations. Others concur that studies of targeted populations may provide important opportunities to uncover novel findings to support best practices for successful engagement with special populations. $^{10,11}$

In an effort to build evidence that is coherent and to facilitate comparisons across studies, we identified four key enablers from the respondents to enhance engagement. The first theme a "focus on positive impacts" has similarities to other studies which suggest stakeholders may be more willing to engage in research where there is an emphasis on understanding the importance of individual contributions and confirmation that individual views collectively achieve meaningful results for others. ${ }^{33}$ Moreover, stakeholders need to feel they are important members of the research team in order to sustain their engagement. ${ }^{13}$ The need for trust and support can be achieved through face-to-face meetings, and making time to socialize with others on the team has been suggested in studies of generic stakeholders ${ }^{13,30-33}$ and is congruent with our second study theme, "build connections". The third enabler theme "offer financial assistance" is thought by some to be key to engagement. ${ }^{6,13,30}$ PCORI developed a model suggesting varying levels of patient financial compensation based on level of engagement. ${ }^{6}$ This approach requires advanced planning with required resources. The fourth enabler theme "creating supportive environments" aligns with other reports of learning how to work together, ${ }^{34}$ and a shared understanding of team roles to ensure equity and respect. ${ }^{6,9,26-29}$ Several papers highlighted supports needed for research training to stakeholders. ${ }^{6,9,31-34}$ Some suggest community-based actions directed to the public at large using radio, television, and digital communication tools to improve understanding of research and the importance of stakeholder engagement in health care research with the general public. ${ }^{34}$ In contrast, others warn against stakeholder training fearing a "super patient" may result and risk losing their lay point of view. ${ }^{32}$

\section{Mapping Study Findings to a Modified Theory}

In an effort to build evidence on engagement that can facilitate comparison across studies to improve participation, we modified an individual level theory on health behavior to fit our study findings. While the application of one modified theory will not adequately cover all factors that influence SER, mapping our findings is a beginning effort to consider common measures to 


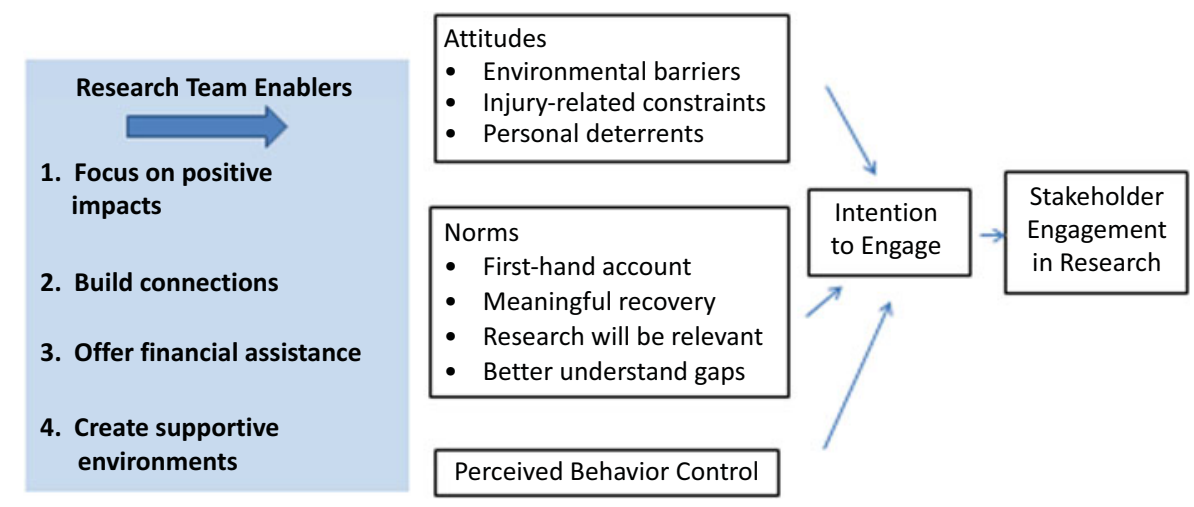

Figure 2: Conceptual framework for stakeholder engagement in research adapted from Ajzen's ${ }^{35}$ theory of planned behavior.

recruit, support, and evaluate SER. Our effort to fit the study findings to a Theory of Planned Behavior (TPB $)^{35}$ required modifications and was an attempt to explore how individual stakeholder factors may relate to steps to initiate and improve engagement in future studies. TPB posits that behavioral intention is a predictor of actual behavior. The theory considers three constructs as important determinants for behavior: (1) attitudes toward the behavior, (2) subjective norms or the expectations of the social environment, and (3) perceived behavior control. The implications of these three constructs suggest beliefs and perceptions are useful for predicting and influencing behavior intention and intention has been demonstrated to predict behavior, in this case research engagement. However, intention may not always convert to action because of other barriers, such as lack of confidence or personal skill. ${ }^{36} \mathrm{We}$ interpret the modified TPB to suggest that a more favorable attitude toward research participation, together with improving socially acceptable action of engagement in research and with greater perceived control (meaning confidence that your voice counts in the overall picture of the research) then the net result could be an increased likelihood for a stakeholder to participate in the behavior of engagement. Furthermore, we propose to modify TPB by the application of the four enablers (see Figure 2). It is important to acknowledge that the behavior of engagement involves two sets: the stakeholders and the researchers. Therefore, differences in the researcher's approachability can also affect stakeholder engagement. Important interventions could be designed to focus on the researcher facilitating the four enablers. Future research may test the proposed modified theory to assess the impact on engagement.

\section{Limitations}

The study participants were limited to self-selecting adults with personal or professional experience with concussion attending a brain injury conference in a narrow geographical region. By attending a brain injury conference, the study sample was already demonstrating a certain level of engagement and may have been more inclined to further participate in research, compared to a standard concussed population. Half of the respondents were rehabilitation health care providers, and their views may be more favorable toward engagement as compared to the general population. The respondents were not representative of those living in northern and remote regions of the province where perspectives on engagement may look very different. Many other factors may also influence SER such as gender, race, socioeconomic status, occupation, and previous research experience. There is a wide variety of potential stakeholders for concussion, and we tapped into a small subset.

\section{Conclusions}

Increasing SER has become a key area of focus to improve research quality and relevance. However, there is no roadmap to guide researchers on how to do so. There may be specific nuances at play with injury-specific stakeholders that require researchers to consider a balance between reducing inhibitors while supporting enablers. Despite the study limitations, there is practical value to consider theory to model engagement findings to support future studies in order to plan, implement, evaluate, and sustain SER. Only when authors report specific strategies and their effectiveness to engage stakeholders will it be possible to compare and to identify the best practices in concussion research.

\section{ACKNOWLedgements}

We sincerely thank Ontario Brain Injury Association and the study subjects for their participation.

\section{CONFLict of InTERest}

The authors have no conflict of interest to declare.

\section{Statement of Authorship}

All authors contributed to the study design, questionnaire development, analysis and review of the manuscript.

\section{REFERENCES}

1. Brett J, Staniszewska S, Mockford C, et al. Mapping the impact of patient and public involvement on health and social care research: a systematic review. Health Expect. 2012;17(5):637-650.

2. Domecq, JP, Prutsky, G, Elraiyah, T, et al. Patient engagement in research: a systematic review. BMC Health Serv Res 2014; 14:89.

3. Shen S, Doyle-Thomas KAR, Beesley L, et al. How and why should we engage parents as co-researchers in health research? A scoping review of current practices. Health Expect. 2017;20(4):543-54.

4. Manafo E, Petermann L, Mason-Lai P, Vandall-Walker V. Patient engagement in Canada: a scoping review of the "how" and "what" of patient engagement in health research. Health Res Policy Syst. 2018;16:5-11. 
5. National Institute for Health Services. INVOLVE. Public involvement in research: values and principles framework. Eastleigh: INVOLVE; 2015. http://www.invo.org.uk/wp-content/uploads/ 2017/08/Values-Principles-framework-Jan2016.pdf; accessed April 30, 2018.

6. Patient-Centered Outcomes Research Institute (PCORI). https:// www.pcori.org; accessed April 30, 2018.

7. Canadian Institutes of Health Research. Evaluation of the Strategy for Patient-Oriented Research - CIHR; 2016. http://www.cihrirsc.gc.ca.myaccess.library.utoronto.ca/e/49937.html\#section1-2; accessed April 15, 2018.

8. Abelson J, Li K, Wilson G, Shields K, Schneider C, Boesveld S. Supporting quality public and patient engagement in health system organizations: development and usability testing of the Public and Patient Engagement Evaluation Tool. Health Expect. 2016;19(4):817-27.

9. Haywood C, Martinez G, Pyatak EA, Carandang K. Engaging patient stakeholders in planning, implementing, and disseminating occupational therapy research. Am J Occup Ther. 2019; 73(1):1-9.

10. McCarron TL, Moffat K, Wilkinson G, et al. Understanding patient engagement in health system decision-making: a co-designed scoping review. Syst Rev. 2019;8(1):97.

11. Ray KN, Miller E. Strengthening stakeholder-engaged research and research on stakeholder engagement. J Comp Eff Res. 2017;6(4):375-89.

12. Esmail L, Moore E, Rein A. Evaluating patient and stakeholder engagement in research: moving from theory to practice. J Comp Eff Res. 2015;4(2):133-45.

13. Goodman MS, Thompson S. The science of stakeholder engagement in research: classification, implementation, and evaluation. Translational Behavioral Medicine. 2017;7(3):486-91.

14. Milani RV, Lavie CJ, Bober RM, Milani AR, Ventura HO. Improving hypertension control and patient engagement using digital tools. Am J Med. 2017;130(1):14-20.

15. Puts MTE, Sattar S, Ghodraty-Jabloo V, et al. Patient engagement in research with older adults with cancer. J Geriatr Oncol. 2017;8(6):391-39.

16. Silver SA, Saragosa M, Adhikari NK,et al. What insights do patients and caregivers have on acute kidney injury and posthospitalisation care? A single-centre qualitative study from Toronto, Canada. BMJ Open. 2018;8(6):1-8.

17. Dewan MC, Rattani A, Gupta S,et al. Estimating the global incidence of traumatic brain injury. J Neurosurg. 2018:1-18.

18. Hunt C, Zanetti K, Kirkham B, et al. Identification of hidden health utilization services and costs in adults awaiting tertiary care following mild traumatic brain injury in Toronto, Ontario, Canada. Concussion. 2016;1(4):CNC21. doi:10.2217/cnc-2016-0009.

19. Hiploylee C, Dufort PA, Davis HS, Wennberg RA, Tartaglia MC, Mikulis D, et al. Longitudinal study of postconcussion syndrome: not everyone recovers. J Neurotrauma. 2017;34:1511-23.

20. Carroll LJ, Cassidy JD, Cancelliere C, et al. Systematic review of the prognosis after mild traumatic brain injury in adults: cognitive, psychiatric, and mortality outcomes: results of the international collaboration on mild traumatic brain injury prognosis. Arch Phys Med Rehabil. 2014;95(3S):S152-73.
21. Foundation ON. Guidelines for Concussion/Mild Traumatic Brain Injury \& Persistent Symptoms; 2018. https://onf.org/3rd-editionguidelines-for-concussion-mild-traumatic-brain-injury-and-persistentsymptoms/https://onf.org/3rd-edition-guidelines-for-concussion-mildtraumatic-brain-injury-and-persistent-symptoms/

22. Ponsford J, Nguyen S, Downing M, et al. Factors associated with persistent post-concussion symptoms following mild traumatic brain injury in adults. J Rehabil Med. 2019;51(1):32-9.

23. Reed N, Leeder K, Zemek R et al. Patient engagement in pediatric concussion research. CMAJ. 2018;190(Suppl):S28-30.

24. Hunt C, Michalak A, Lefkimmiatis C, et al. Exploring concussion awareness in hockey with a First Nations community in Canada. Public Health Nurs. 2018;35(3):202-10.

25. OBIA Ontario Brain Injury Association http://obia.ca; accessed September 30, 2019.

26. International Association for Public Participation. IAP2PublicParticipationSpectrum.International Association for Public Participation 2014; https://www.iap2.org/mpage/Home; accessed April 30, 2018.

27. Corbin J, Strauss A. Basics of qualitative research: techniques and procedures for developing grounded theory. Thousand Oaks: Sage; 2008.

28. Baczynska AM, Shaw SC, Patel HP, Sayer AA, Roberts HC. Leaning from older peoples' reasons for participating in demanding, intensive epidemiological studies: a qualitative study. BMC Med Res Methodol. 2017;17(167):1-9.

29. Carroll Embuldeniya G, Abelson J, et al. Questioning patient engagement: research scientists' perceptions of the challenges of patient engagement in a cardiovascular research network. Patient Prefer Adherence. 2017;11:1573-83.

30. Vat LE, Ryan D, Etchegary H. Recruiting patients as partners in health research: a qualitative descriptive study. Res Involv Engagem. 2017;3:5-14. doi: 10.1186/s40900-017-0067-x.

31. Snape D, Kirkham J, Britten N, et al. Exploring perceived barriers, drivers, impacts and need for evaluation of public involvement in health and social care research: a modified Delphi study. BMJ Open 2014;4(6). https://bmjopen.bmj.com/content/4/6/e004943; accessed April 20, 2019.

32. Black A, Strain K, Wallsworth C, et al. What constitutes meaningful engagement for patients and families as partners on research teams? J Health Serv Res Policy. 2018;23(3):158-167.

33. Callari TC, Moody L, Saunders J, Ward G, Woodley J. Stakeholder requirements for an ethical framework to sustain multiple research projects in an emerging living lab involving older adults. J Empir Res Hum Res Ethics. 2019: 1556264619873790 .

34. Hamilton CB, Hoens AM, Backman CL, et al. An empirically based conceptual framework for fostering meaningful patient engagement in research. Health Expect 2018;21:396-406. doi: 10.1111/ hex.12635; accessed July 42018.

35. Ajzen I. The theory of planned behavior. Organizational Behav Human Decis. 1991;50:179-211.

36. Kroshus E, Baugh CM, Daneshvar DH, Viswanath K. Understanding concussion reporting using a model based on the theory of planned behavior. J Adolesc Health. 2014;54(3): 269-74. 